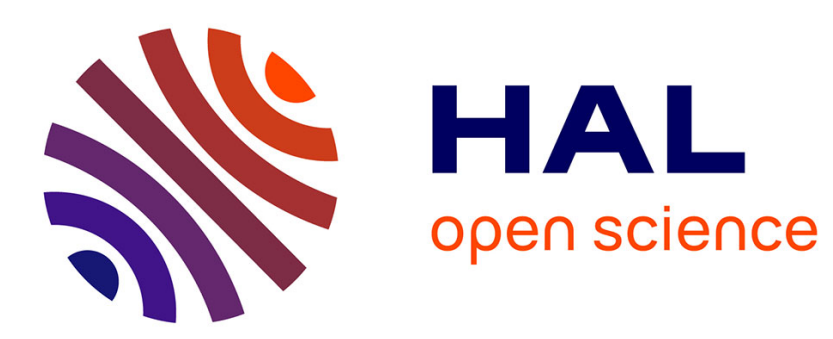

\title{
Effects of pre-commercial thinning on growth and reproduction in post-fire regeneration of Pinus halepensis Mill
}

\author{
Irene Ruano, Encarna Rodríguez-García, Felipe Bravo
}

\section{To cite this version:}

Irene Ruano, Encarna Rodríguez-García, Felipe Bravo. Effects of pre-commercial thinning on growth and reproduction in post-fire regeneration of Pinus halepensis Mill. Annals of Forest Science, 2013, 70 (4), pp.357-366. 10.1007/s13595-013-0271-2 . hal-01201485

\section{HAL Id: hal-01201485 \\ https://hal.science/hal-01201485}

Submitted on 17 Sep 2015

HAL is a multi-disciplinary open access archive for the deposit and dissemination of scientific research documents, whether they are published or not. The documents may come from teaching and research institutions in France or abroad, or from public or private research centers.
L'archive ouverte pluridisciplinaire HAL, est destinée au dépôt et à la diffusion de documents scientifiques de niveau recherche, publiés ou non, émanant des établissements d'enseignement et de recherche français ou étrangers, des laboratoires publics ou privés. 


\title{
Effects of pre-commercial thinning on growth and reproduction in post-fire regeneration of Pinus halepensis Mill
}

\author{
Irene Ruano • Encarna Rodríguez-García • Felipe Bravo
}

Received: 20 July 2012 / Accepted: 7 February 2013 /Published online: 8 March 2013

(C) INRA and Springer-Verlag France 2013

\begin{abstract}
- Context Excessive recruitment in post-fire regeneration of Pinus halepensis can require pre-commercial thinning. The 1994 Moratalla fire (Spain) and the thinning applied there since 2004 provided good conditions for testing precommercial thinning effectiveness.

- Aims To analyse pre-commercial thinning effects on tree size, reproductive potential, stem biomass and annual growth in 15-year-old saplings.

- Methods Twenty nine circular plots (5 m radius) were established based on (1) years since thinning and (2) aspect. Non-thinned plots were included as controls. Sapling variables were measured and pine cones were counted and classified according to maturity. Three saplings per plot were felled, five sample disks were extracted from each and tree rings were analysed with Windendro ${ }^{\circledR}$ software.

- Results Sapling size, annual growth and stem biomass were higher in thinned plots than in control plots 2-4 years after thinning. Annual growth declined five years after

Handling Editor: Eric Rigolot

Contribution of the co-authors Irene RUANO: designed the experiment, conducted measurements on the field, ran the data analysis and wrote the first version of the paper.

Encarna RODRÍGUEZ-GARCÍA: designed the experiment, conducted measurements on the field, ran the first data analysis and improved the first version of the paper with different suggestions.

Felipe BRAVO: designed the experiment, supervised the work, improved the manuscript with different comments and coordinated the research project
\end{abstract}

Electronic supplementary material The online version of this article (doi:10.1007/s13595-013-0271-2) contains supplementary material, which is available to authorized users.

I. Ruano $(\triangle) \cdot$ E. Rodríguez-García $\cdot$ F. Bravo

Sustainable Forest Management Research Institute, University

of Valladolid-INIA, Avda. Madrid s/n,

34004 Palencia, Spain

e-mail: irene@pvs.uva.es thinning. Cone counts were higher $2-5$ years after thinning, depending on the cone type. Aspect influenced some variables.

- Conclusion Thinning accelerated stand maturity but positive effects were indiscernible until 2-5 years later. Serotinous cones, which are fundamental to regeneration after fire, increased in number after 5 years. The effects of aspect were inconclusive due to interactions with years since thinning.

Keywords Mediterranean forest · Dendroecological analysis · Annual growth $\cdot$ Reproductive potential $\cdot$ Stem biomass $\cdot$ Post-fire regeneration

\section{Introduction}

Although fire is considered a perturbation inherent to Mediterranean basin forests because of its high frequency and the adaptation of some species to fire, global changes in climate and land use are directly affecting fire dynamics (Moriondo et al. 2006). Climate forecasts for the Mediterranean region in the next decades indicate higher temperatures and lower precipitation irregularly distributed between and within years (IPCC 2007). In such a scenario, relative humidity will be lower, forest fuel drier and fire risk higher; burned areas and the intensity and frequency of fires are expected to increase (Moriondo et al. 2006). Mediterranean forests could be at risk if fires become more frequent than the mature age of the species.

Resprouting or serotinity are adaptations to ensure regeneration after a fire. Pinus halepensis and Pinus brutia Ten., two of the most important species in the Mediterranean ecosystems, have serotinous cones that retain mature seeds for dispersal after fire (Daskalakou and Thanos 1996, Boydak 2004).

The presence of serotinous cones and the number of seeds they carry are key factors for good post-fire 
regeneration of the entire Pinus genus (Vega 2003), and especially Aleppo Pine-P. halepensis-(Ne'eman et al. 2004). Post-fire regeneration of $P$. halepensis is usually more than adequate, because it is adapted to xeric conditions and its serotinous cones open after fire to regenerate the stand (Daskalakou and Thanos 1996). When Aleppo Pine seedling density is excessive, pre-commercial thinning interventions become necessary (Vega 2003). These treatments also reduce fire risk by controlling fuel continuity.

$P$. halepensis can grow in difficult environmental conditions and is a main species for restoring arid and semi-arid Mediterranean areas. However, mono-specific P. halepensis plantations could have negative effects: in large plantations soil humidity is lower than in other floristic communities, successional processes are slower and wildlife biodiversity is reduced due to the homogenization of the landscape and the reduction of habitat diversity (Maestre and Cortina 2004). P. halepensis plantations in Mediterranean areas are a common recourse for establishing tree cover and conserving soil in degraded areas. In the first phases, this species improves the vertical structure of the forest, but the richness and diversity of undergrowth species is diminished (Chirino et al. 2006). However, timely treatments such as thinning or pruning could improve conditions for understory plant species in mono-specific plantations (Navarro et al. 2010a).

However, the benefits and risks of thinning to reduce sapling density after a fire are not well-defined. Positive effects of thinning in post-fire regeneration of $P$. halepensis have been observed for cone production, structural pattern and plant diversity (González-Ochoa et al. 2004; De las Heras et al. 2007; Moya et al. 2009); but negative effects have also been observed after treatment, such as higher levels of defoliation from Pachyrhinus squamosus Kiesenwetter (González-Ochoa et al. 2002). Moreover pre-commercial thinning influenced also allometric equations and carbon partitioning in $P$. halepensis regenerated after fire (De las Heras et al. 2012).

The objective of this study was to analyse the effect of precommercial thinning on post-fire regeneration of $P$. halepensis in the Mediterranean area. To accomplish this objective, postfire regeneration saplings were analysed considering two factors: (1) years since the thinning (2, 3, 4 or 5) and (2) aspect (north or south). The pre-commercial thinning was carried out by the Murcia Regional Forest Service from 2004 to 2007 so the data obtained is directly related with forest management strategy and will serve to define the most appropriate strategy for this type of situations.

\section{Material and methods}

P. halepensis regeneration was analysed in the area burned in the 1994 Moratalla fire, which destroyed 24,817 ha of forest in south-eastern Spain. Most of the area affected was populated by natural $P$. halepensis stands. Regeneration was so excessive that pre-commercial thinning was carried out from 2004 to 2011 to reduce tree density.

\subsection{Study area and description of pre-commercial thinning}

The study area is located in $P$. halepensis stands affected by the 1994 fire in the Sierra del Cerezo mountain range, near the village of Moratalla, in the province of Murcia (Spain) (Fig. 1). This mountain range, with an elevation of $1,140 \mathrm{~m}$, is located mainly in SW-NE aspect and formed by limestone and dolomitic materials.

The climate is Mediterranean with strong summer drought (low precipitation and very high temperatures in summer mean drought when precipitation is minor than two times mean temperature, Fig. 1) and important rainfalls during winter. Annual mean air temperature is $12.1^{\circ} \mathrm{C}$ and mean annual precipitation is $416 \mathrm{~mm}$ (Rivas-Martínez and Rivas-Sáenz 1996-2009). Accompanying vegetation includes Juniperus oxycedrus L., Daphne gnidium L., Rosmarinus officinalis L., Thymus vulgaris L., Cistus clussi Dunal and tree species such as Quercus ilex subsp. ballota (Desf.) Samp. in xeric areas and Quercus faginea Lam. in more humid areas.

After the Moratalla fire, $P$. halepensis stands regenerated profusely in most areas, with more than 80,000 seedlings/ha in some places (density estimated in control plots). From 2004 to 2011, the Murcia Regional Forest Service carried out a pre-commercial thinning intervention project in areas where initial density was higher than 2,000 saplings/ha. Semi-systematic pre-commercial thinning was implemented mechanically by de-brushing strips of land $3 \mathrm{~m}$ wide and complemented by manual pre-commercial thinning between strips, to obtain a final density of 1,600 trees/ha. All remaining saplings were pruned and woody coarse debris was triturated. To improve stand biodiversity, shrubs and Quercus species were not eliminated. This treatment was applied yearly from 2004 to 2007 in the area of the study and the sampling took place in 2009.

\subsection{Sampling design and data}

This analysis of the effects of thinning on the post-fire regeneration was based on two factors: (1) years since the thinning (2, 3, 4 or 5) and (2) aspect (north or south). Control areas where thinning had not yet been applied were included. In June of 2009, 29 circular plots (5 m radius) were established to represent all factor combinations except ' 2 years after thinning, north aspect', which was not found in the study area. Three replicate plots for each year and aspect were sampled, and four control plots (non-thinned stand) for each aspect were established. The plots were divided into three sectors, with the first division line always 


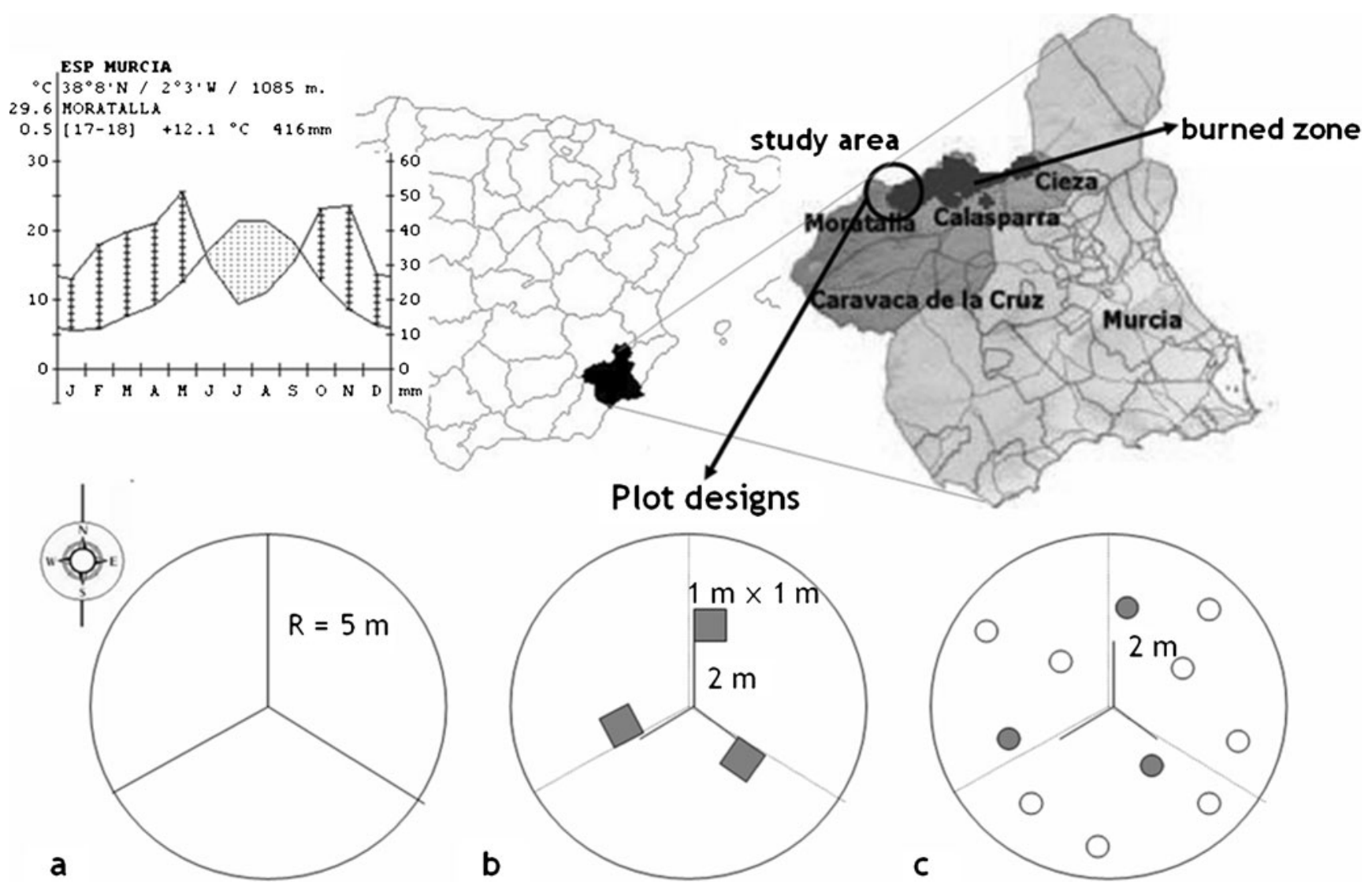

Fig. 1 Location of the burned zone and the study area with a climodiagram of Moratalla (Murcia) and outlines of plot designs. Climodiagram from Rivas-Martínez and Rivas-Sáenz (1996-2009)

indicating north for uniform referencing in the sampling process (Fig. 1a).

In the south-aspect plots and controls, total height (accuracy $\pm 1 \mathrm{~cm}$ ) and basal diameter (accuracy $\pm 1 \mathrm{~mm}$ ) of all saplings were measured. Diameter at breast height was not measured because most of the saplings were of insufficient height. Three types of cones were also counted for each sapling following the methodology proposed by De las Heras et al. (2007): new (small, green cones less than two years old), mature brown (closed mature brown cones between 2 and 3 years old) and serotinous (closed grey cones over 3 years old). Open cones were not counted. Finally, three saplings were selected and felled for dendroecological analysis of annual growth.

Since post-fire density is usually higher in north-aspect $P$. halepensis stands than in south-aspect stands (Pausas et al. 2004), sampling in north-aspect control plots was adjusted accordingly. Three $1 \mathrm{~m} \times 1 \mathrm{~m}$ sub-plots were marked $2 \mathrm{~m}$ from the centre of the plot on each of the division lines (Fig. 1b). All saplings and cones in the sub-plots were counted and the total height and basal diameter were measured for three selected saplings per sub-plot. One sapling per sub-plot was then selected and felled for dendroecological analysis of annual growth.

\subsection{Dendroecological analysis}

Dendroecological methods were implemented to analyse annual growth (accuracy $\pm 1 \mathrm{~mm}$ ). Along the division lines of the plots, the sapling nearest to the point $2 \mathrm{~m}$ from the centre was selected (Fig. 1c). However, in north aspect control plots, the sapling was selected from the centre of the sub-plot and felled. Five disks were extracted: the first from the base and the remaining four from points distributed uniformly along the stem. The disks were sanded for ring identification with Windendro ${ }^{\circledR}$ software (Regent Instrument Inc., 2002).

Annual growth data were obtained from the basal disk and stem biomass data were obtained from all the disks of each sapling. Moreover rings were counted to know the age of the saplings. Most of them were 14 years old (date of first ring 1995). Sapling volume estimates were based on truncated cones between disks and a cone from the last disk to the apex. Basic density was calculated with Kollmann's formula (1959), using 0.610 as the normal density of $P$. halepensis (Centre de la Propietat Forestal 2004). Sapling stem biomass was then calculated by multiplying estimated sapling volume and basic density. 


\subsection{Variables}

The variables were divided into four groups (Table 1): size (basal diameter and height), reproductive potential (number of cones), biomass and annual growth. All plot saplings were included in the analysis of reproductive potential; saplings selected for dendroecological analysis were used to analyse stem biomass and annual growth. Size was analysed first by including all saplings in the plot and then using only the selected saplings.

\subsection{Statistical analysis}

\subsubsection{Size}

Tree size was studied in two ways. First, an analysis of variance (ANOVA with a Tukey test) was applied to all saplings in the plot using two factors: years since thinning and aspect. Second, the same factors were used in an analysis of covariance (ANCOVA with a Tukey test) applied to the saplings selected for dendroecological analysis, with growth before thinning as a covariable. Calculating growth before thinning we considered 10 years for control plots and plots treated 5 years ago, 11 years for plots treated 4 years ago, 12 years for plots treated 3 years ago and 13 years for plots treated 2 years ago. Slope and elevation were also considered as a covariable, but were not significant. The square root transformation was applied to size data in all tests, in order to satisfy normality and homoscedasticity assumptions. Variables are shown with transformation.

\subsubsection{Reproductive potential}

A mixed linear model was used to analyse reproductive potential (number of cones per hectare) because none of the variable transformations allowed for analysis with general linear models. Three factors were considered: years since thinning, aspect and cone type. For this test, the logarithm plus 1 transformation was used for reproductive potential which is shown with transformation. The mathematic formulation of the model is as follows:

$y_{\mathrm{ijk} l}=\mu+a_{\mathrm{i}}+\beta_{\mathrm{j}}+\gamma_{\mathrm{k}}+a \beta \gamma_{\mathrm{ij}}+a \gamma_{\mathrm{ik}}+\beta \gamma_{\mathrm{jk}}+a \beta \gamma_{\mathrm{ijk}}+\varepsilon_{\mathrm{ijkl}}$

where: $i \equiv 1,2,3,4 ; j \equiv 1,2 ; k \equiv 1,2,3 ; l \equiv 1,2, \ldots 29$; and $y_{i j k l} \equiv$ variable to analyse for Plot 1 , years since thinning $i$, aspect $j$ and cone type $k ; \mu \equiv$ general mean effect; $\alpha_{i} \equiv$ effect of years since thinning $i$ (i=nonthinned, 2, 3, 4, 5 years after thinning); $\beta_{j} \equiv$ effect of aspect $j$ ( $j=$ North, South); $\gamma_{k} \equiv$ effect of cone type $k$ ( $k=$ new, mature, serotinous); $\alpha \beta_{i j}$ =effect of interaction between years since thinning $i$ and aspect $j ; \alpha \gamma_{i k} \equiv$ effect of interaction between years since thinning $i$ and cone type $k ; \beta \gamma_{j k} \equiv$ effect of interaction between aspect $j$ and cone type $k ; \alpha \beta \gamma_{i j k} \equiv$ effect of interaction between years since thinning $i$, aspect $j$ and cone type $k ; \varepsilon_{i j k l} \equiv$ random error for Plot 1 , with years since thinning $i$, aspect $j$ and cone type $k$ having normal $\left(0, \sigma_{j}^{2}\right)$ and independent distributions.

\subsubsection{Stem biomass}

ANCOVA with a Tukey test considering growth before thinning as a covariable was used to analyse the influence of thinning during the first years on stem biomass. Elevation and slope were also considered as covariables, but were not significant. The square root transformation was used on biomass data in order to satisfy normality and homoscedasticity assumptions. Variable is shown with transformation.
Table 1 Characteristics of the variables analysed: sampling size $(n)$, mean, maximum, minimum and standard deviation (sampling size of height is minor than basal diameter due to a failure in data sampling). Annual growths were calculated considering the date of the thinning

\begin{tabular}{|c|c|c|c|c|c|c|c|}
\hline & & & $n$ & Mean & Max & Min & $\begin{array}{l}\text { Standard } \\
\text { deviation }\end{array}$ \\
\hline \multirow{5}{*}{$\begin{array}{l}\text { Saplings of } \\
\text { the plot }\end{array}$} & \multirow[t]{2}{*}{ Size } & Basal diameter $(\mathrm{cm})$ & 266 & 5.23 & 16.40 & 0.35 & 3.06 \\
\hline & & Height (m) & 265 & 1.95 & 5.50 & 0.30 & 0.91 \\
\hline & \multirow{3}{*}{$\begin{array}{l}\text { Reproductive } \\
\text { potential (cones/ha) }\end{array}$} & New cones & 29 & $5,540.35$ & $16,552.11$ & 0.00 & 4592.53 \\
\hline & & Mature cones & 29 & $5,120.79$ & $30,000.00$ & 0.00 & 7077.09 \\
\hline & & Serotinous cones & 29 & $1,011.39$ & $6,666.667$ & 0.00 & 1567.86 \\
\hline \multirow{9}{*}{$\begin{array}{l}\text { Selected } \\
\text { saplings }\end{array}$} & \multirow[t]{2}{*}{ Size } & Basal diameter $(\mathrm{cm})$ & 79 & 5.17 & 12.55 & 0.50 & 2.63 \\
\hline & & Height (m) & 79 & 1.95 & 5.50 & 0.66 & 0.85 \\
\hline & Stem biomass $(\mathrm{kg})$ & & 79 & 0.097 & 0.904 & 0.002 & 0.128 \\
\hline & \multirow{6}{*}{$\begin{array}{l}\text { Annual growth after } \\
\text { thinning }(\mathrm{mm})\end{array}$} & 1 year after & 165 & 2.09 & 8.91 & 0.24 & 1.75 \\
\hline & & 2 years after & 63 & 2.94 & 7.20 & 0.29 & 1.69 \\
\hline & & 3 years after & 54 & 4.15 & 19.99 & 0.58 & 3.10 \\
\hline & & 4 years after & 36 & 4.06 & 8.17 & 1.15 & 1.77 \\
\hline & & 5 years after & 18 & 2.80 & 4.60 & 0.96 & 0.95 \\
\hline & & Control (non-thinned) & 80 & 1.27 & 5.55 & 0.18 & 1.10 \\
\hline
\end{tabular}




\subsubsection{Annual growth}

After square root transformation to meet assumptions of normality and homocedasticity, annual growth was also analysed by ANCOVA with a Tukey test. The two factors considered were aspect and years since thinning, but in this case, years since thinning had six levels. The dendroecological analysis made it possible to determine annual growth 1 year after thinning, even though no plots were thinned in 2008. Two covariables were considered for this analysis: growth before thinning and total annual precipitation in the current hydrological year (October 1st to September 30th). Elevation and slope were also tested as covariables but they were not significant. Precipitation was used as a covariable because rainfall is a key variable for $P$. halepensis growth (Olivar et al. 2012) and strong climatic differences were recorded between 2004 and 2007, the years when the plots were thinned (Table 2). This variable is shown with transformation.

All analyses were performed with the SAS 9.2 statistical package (SAS Institute Inc., USA).

\section{Results}

\subsection{Size}

In the ANOVA, years since thinning, aspect and the interaction between them were significant for both variables of size $(P<0.05)$. Average basal diameter was larger 5 years after thinning, but differences among other plots were less clear. Lower mean basal diameter was found in control plots, where thinning had not been applied; but the differences between these and 2 and 3 years after thinning were not significant (Fig. 2 and Supplementary Table 1). However, basal diameter was significantly larger in plots with south aspect than in those with north aspect (Fig. 2 and Supplementary Table 1).

Regarding the interaction between years since thinning and aspect, mean basal diameter was significantly higher for south aspect in control plots and 5 years after thinning, but higher with north aspect 4 years after thinning. Lower mean basal diameter was observed in control plots with north aspect. There were no significant differences between aspects 3 years after thinning (Supplementary Table 1).

Average height was greater 5 years after thinning. Clear differences were not observed among the other time levels, though lower mean height was observed 3 years after thinning. There were no significant differences between control plots and 2 years after thinning. Average height was greater with north aspect than with south aspect (Fig. 2 and supplementary Table 2).

Finally, analysis of interactions between factors revealed greater heights for north aspect, with two exceptions: tree height was greater in control plots with south aspect and 3 years after thinning showed no differences between aspects. Greater average heights were obtained 5 years after thinning with north aspect and lower average heights were recorded 3 years after thinning with north aspect (Supplementary Table 2).

The saplings selected for dendroecological analysis were also used for the second size analysis, because the dendroecological analysis allowed us to determine growth before thinning. ANCOVA was applied to the saplings, with growth before thinning as covariable. Years since thinning and interaction between factors were found to be significantly related to basal diameter, while years since thinning and aspect were significantly related to height, $(P<0.05)$.

Higher mean basal diameters were found 5 years after thinning, but there were no significant differences in mean basal diameter between 2 and 4 years after thinning (Fig. 3 and Supplementary Table 3). Lower mean basal diameter was recorded for control plots where thinning had not been applied.

Interaction between factors showed larger mean basal diameters in plots with north aspect 4 years after thinning and in control plots with south aspect. There were no significant differences regarding aspect for the other years. Higher basal diameter was recorded 5 years after thinning with south aspect and lower basal diameter in control plots with North aspect (Supplementary Table 3).

Greater results for average height were obtained 5 years after thinning, though there were no significant differences between these and 4 years after thinning. Lower average heights were obtained for control plots and 2 and 3 years
Table 2 Climatic data: mean annual temperature (degrees Celsius) since 1st October to 30th September; Total annual precipitation (in millimetre) since 1st October to 30th September; total spring precipitation (in millimetre) considering March, April and May; total winter precipitation (in millimetre) considering December, January and February. Mean annual temperature of 2008 was estimated with a local lineal regression and available data

\begin{tabular}{|c|c|c|c|c|c|}
\hline & 2004 & 2005 & 2006 & 2007 & 2008 \\
\hline Mean annual temperature $\left({ }^{\circ} \mathrm{C}\right)$ & 14.3 & 14.5 & 14.4 & 14.6 & 14.0 \\
\hline Total annual precipitation $(\mathrm{mm})$ & 775.3 & 359.0 & 410.0 & 643.4 & 483.9 \\
\hline Total spring precipitation (mm) & 358.0 & 63.5 & 160.5 & 257.9 & 167.0 \\
\hline Total winter precipitation (mm) & 112.5 & 212.0 & 112.0 & 122.5 & 102.5 \\
\hline
\end{tabular}


Fig. 2 Mean values and confidence intervals of transformed size variables of all saplings of the plot depending on years since thinning and aspect: basal diameter (in centimetre), height (in metre) and comparison between factor levels: levels with same letters means no significant differences $(P>0.05)$
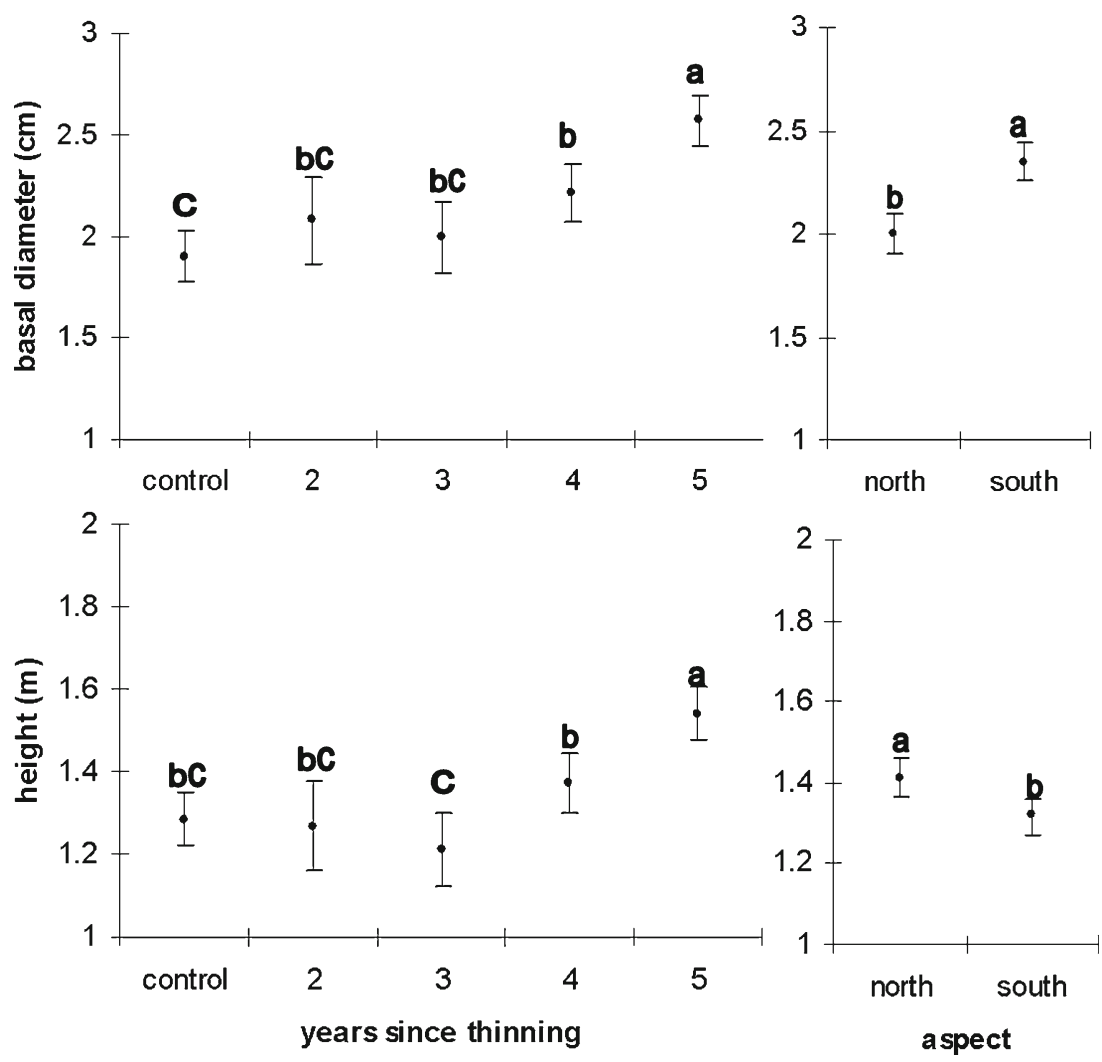

after thinning, with no significant differences among them. Finally, average height was significantly greater in plots with north aspect than in those with south aspect (Fig. 3 and Supplementary Table 4).

Size was analysed for all saplings by ANOVA. The saplings selected for dendroecological analysis were then analysed by ANCOVA, using growth before thinning as a covariable. The results were more conclusive with previous growth as a covariable, and $R^{2}$ square increased ( 0.376 vs 0.814 for basal diameter and 0.233 vs. 0.625 for height) with a covariable.

\subsection{Reproductive potential}

Based on a $P$ value of 0.05 , type, years since thinning and the interaction between years and type were found to be significant. New cones were significantly more abundant and mature cone counts were significantly higher than serotinous cone counts. Higher average cone counts were observed 5 years after thinning. Lower results were observed 2 years after thinning, though there were no significant differences between these and control plots and 3 and 4 years after thinning (Supplementary Table 5).

Average new cone counts were significantly higher 2 years after thinning, though there were no significant differences between these and 3 and 5 years after thinning. Lower results for new cones were observed in control plots, though there were no significant differences between these and 3 and 4 years after thinning. Mature cone count averages were higher 5 years after thinning and there were no significant differences between these and 4 after thinning.
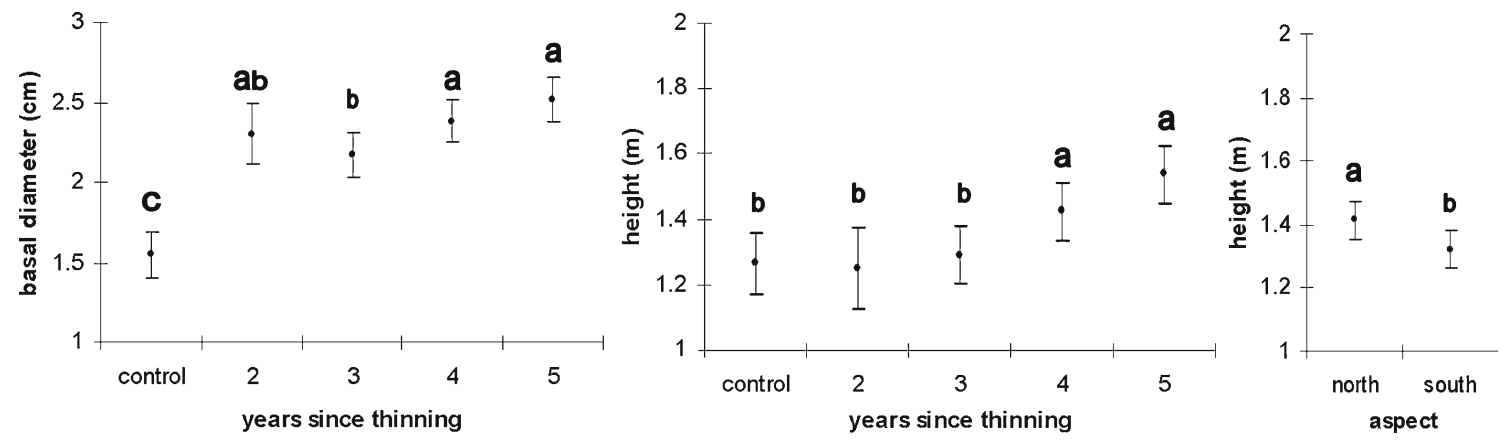

Fig. 3 Mean values and confidence intervals of transformed size variables of selected saplings depending on years since thinning and aspect: basal diameter (in centimetre), height (in metre) and comparison between factor levels: levels with same letters means no significant differences $(P>0.05)$ 
Lower results for mature cones were observed in control plots, though there were no significant differences between these and 2 and 3 years after thinning. Serotinous cone counts increased significantly 5 years after thinning and there were no significant differences between control plots and other thinned plots (Fig. 4 and Supplementary Table 5).

New cones were significantly more abundant than new and serotinous cones 2 and 3 years after thinning. However, mature cones were significantly more abundant than new cones 4 years after thinning. There were no differences between new and mature cones 5 years after thinning. Serotinous cones always had lower results, although there were no significant differences between these and mature cones in control plots and 2 and 3 after thinning. Finally, there were no significant differences among cone types in control plots (Fig. 4 and Supplementary Table 5).

\subsection{Stem biomass}

Years since thinning and aspect were significant $(P<0.05)$, but interaction between factors was not significant. The largest average results were obtained 4 and 5 years after thinning, respectively, and the differences between them were not significant. The smallest average stem biomass was recorded for control plots (Fig. 5 and Supplementary Table 6) and average stem biomass was found to be significantly greater in plots with north aspect than in plots with south aspect.

\subsection{Annual growth}

Years since thinning and interaction between years and aspect were found to be significant but aspect was not significant $(P<0.05)$. Lower average results were obtained in control plots though there were no significant differences between these and 1 year after thinning. Higher results were obtained in 3 and 4 years after thinning with no significant differences between them. There were also no significant

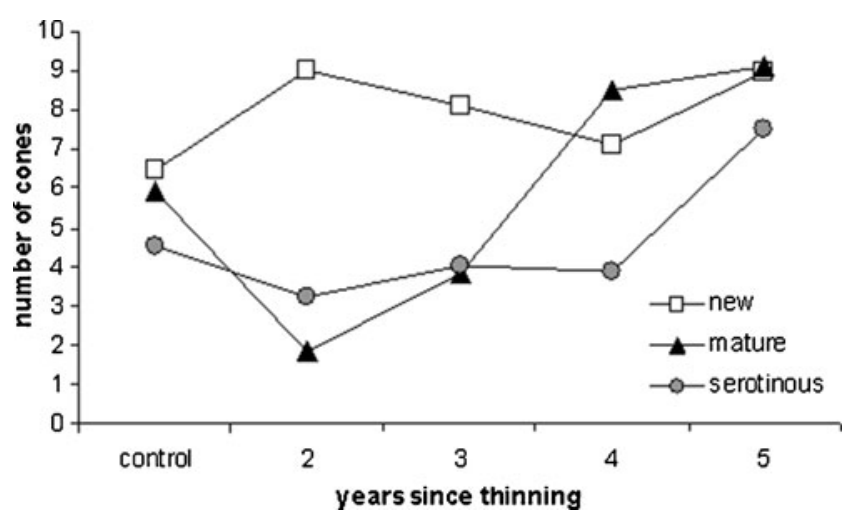

Fig. 4 Mean values of transformed potential reproductive depending on years since thinning considering three types of cones differences between 2 and 5 years after thinning. This reveals that there was no annual growth increment 1 year after thinning in thinned plots; then growth peaked 3-4 years after thinning and decreased after 5 years, but was still higher than in control plots (Fig. 5 and Supplementary Table 7). Finally, in thinned plots, there was no significant interaction between years since thinning and aspect; but in control plots annual growth was greater for south aspect than for north aspect.

\section{Discussion}

Our results support the current view that pre-commercial thinning operations applied to post-fire regeneration in $P$. halepensis stands have a generally positive effect on size, reproductive potential, biomass and annual growth, all of which accelerate tree maturation. González-Ochoa and De las Heras (2002) argued that intense silvicultural treatments could generate a temporal decline of the stand, followed by damage after a few years from defoliator species such as P. squamosus. However, no damage or disease was found in the present work, indicating that thinning did not provoke a decline.

Other studies have analysed the effect of thinning on diameter growth of Pinus pinaster Ait. (Madrigal et al. 2004) and P. halepensis (Navarro et al. 2010b) in Spain, obtaining similar results to those of the present work. They found that thinning had a positive effect in all cases, with higher diameters 1 year after treatment; while our results did not show increased basal diameters until 2 or 4 years after thinning, depending on the analysis applied. Tsitsoni et al. (2004) also observed higher basal diameters for P. brutia post-fire regeneration 10 years after thinning in Greece.

Dendroecological analysis made it possible to calculate annual growth for previous years with greater accuracy, to include inter-annual variability by total annual precipitation and to determine growth one year after thinning. Annual growth was lower in control plots, but there were no significant differences between these and 1 year after thinning. The positive effects of thinning were not substantial until 2 years later. Dendroecological analysis showed the effect of thinning over time: maximum growth occurred 3 and 4 years after thinning and was minor 5 years after thinning, though still higher than in control plots. Navarro et al. (2010b) also observed higher diameters after thinning, but in their study diameter growth began to decrease 4 years after pre-commercial thinning.

This growth response could be due to the incorporation of soil nutrients from triturated woody debris, left in the stand after thinning. Slash management effect has been investigated for different species across the word, especially for commercial forest plantations. For example, (Smethurst and Cambiar 1990) analysed different slash and litter management in Pinus radiata D. Don plantations in a 


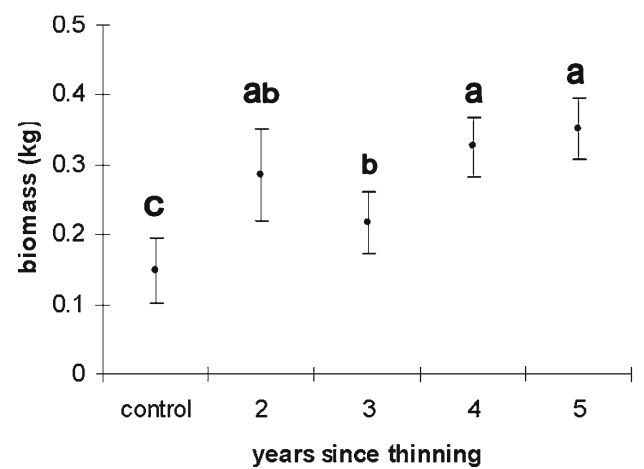

Fig. 5 Mean values and confidence intervals of transformed stem biomass (in kilogramme) and transformed annual growth (in millimetre) of selected saplings depending on years since thinning
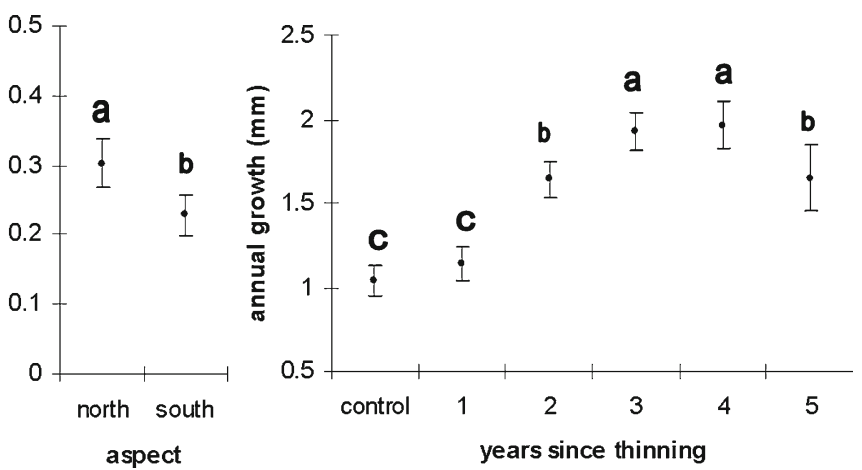

Mediterranean climate in South Australia and observed that carbon in the soil surface increased after 4 months but decreased during the next 40 months. Pérez-Batallón et al. (2001) studied $P$. radiata plantations in the north of Spain and they observed no changes in soil microbial biomass although there was a high degree of $\mathrm{N}$ immobilization after 12 months where residues left on site. In the present study, woody debris could supply nutrients although Ganjegunte et al. (2004) observed for P. radiata plantations decomposition rates of slash components were related to substrate quality. Moreover half of the total $\mathrm{C}$ contained in the slash was released after 13 years. According to the effect on water and soil temperature, Smethurst and Cambiar (1990) observed soils without slash or litter cover were warmer and were subjected to greater extremes of temperature. Therefore, in the present work, woody debris could protect saplings for extreme temperatures induced by a greater incidence of solar radiation from removal of sapling cover.

Height results also varied according to the analysis applied. This result differs from other studies, which showed greater height increase 2 years after thinning in $P$. halepensis in Spain (González-Ochoa et al. 2004) and Israel (Ne'eman et al. 1995) , or P. pinaster in Spain (Madrigal et al. 2004). Tistsoni et al. (2004) observed greater height increase one year after thinning for P. brutia in Greece. Our results showed a larger delay period for height increase after thinning.

Analysis of reproductive potential showed short-term increases in cone counts after thinning. These results were similar to others in which thinning was found to have improved the number of cones per hectare 22 months (GonzálezOchoa et al. 2004) and 18 months (Verkaik and Espelta 2006) after thinning. In contrast, De las Heras et al. (2007) found higher numbers of serotinous cones and total cones in thinned plots but did not observe significant differences for new and mature cones between thinned and non-thinned areas.

Serotinous cones were significantly lower and until the fifth year there were no differences between control plots and treated plots. This could be due to the age of the stand, and aspect: comparison between factor levels with same letters means no significant differences $(P>0.05)$

since Verkaik and Espelta (2006) observed that 18 months after thinning serotiny had decreased more in 18- and 22year-old stands than in 10-year-old stands. Goubitz et al. (2004) also observed that the level of serotiny decreased as tree height increased. This first period with a low number of serotinous cones could be a problem if a recurrent fire occurs. A recurrent wildfire in this area could reduce its capacity to recover from fire and even endanger the future of these stands (Eugenio et al. 2006). Eugenio et al. (2006) and Espelta et al. (2008) analysed the structural changes induced by fire recurrence in P. halepensis stands. Density and growth in height and diameter were significantly less in twice-burn areas than once-burnt areas (Eugenio et al. 2006). Espelta et al. (2008) also analysed reproduction ability in once and twice-burn areas and they concluded twice-burnt areas had a 3-year delay in the onset of pine reproduction, a reduction of $52 \%$ in the number of reproductive pines and a $36 \%$ lower mean cone crop per tree. Finally, Espelta et al. (2008) also observed that density of stand and tree height were mainly responsible for the reduction in the reproductive performance. So it is necessary to avoid recurrent wildfires and thinning could be a good tool controlling fuel continuity and indirectly improving size and potential reproductive of the saplings in a short period of time.

Finally, the stem biomass analysis showed higher averages $4-5$ years after thinning and lower averages in control plots. The positive effect of intervention on biomass became apparent 2 years after thinning.

Thinning in post-fire $P$. halepensis regeneration produced short-term improvements in size, reproductive potential, annual growth and stem biomass. Aspect influenced some of these variables, especially in un-thinned zones, but its effects were difficult to clearly discern due to interactions. In the Mediterranean ecosystem, effect of aspect has been analysed due to south aspects receive higher solar radiation and this could affect the vegetation. Vegetation structure and plant species diversity changed significantly separating the north- and south-facing slopes (Kutiel 1992, Sternberg and 
Soshany 2001) but in some cases the effect on some species is no clear. Osem et al. (2009) analysed natural regeneration of $P$. halepensis and it was highly variable among different forest sites in Israel although showed no clear relationship to aspect.

The present study analysed the effect of the pre-commercial thinning on post-fire regeneration of $P$. halepensis. This treatment accelerated stand maturity in terms of diameter, height, annual growth and stem biomass but positive effects were indiscernible until 2-3 years later possibly because of the stress produced by thinning. Reproductive potential increased in new and mature cone counts 2-4 years later. Serotinous cones, which are fundamental to regeneration after a recurrent fire, increased in number after 5 years. Therefore pre-commercial thinning is a good tool to improve post-fire regeneration stands of $P$. halepensis with high density (more than 2,000 saplings/ha). Moreover, it is important to carry out the thinning early ( 5 years after fire, according to De las Heras et al. (2012)) due to the level of serotiny decrease as the time went by (Goubitz et al. 2004; Verkaik and Espelta, 2006) and a recurrent fire could endanger the future of the stand.

Acknowledgments The authors thank the Murcia Regional Forest Service for technical support and the Agencia Estatal de Meteorología (AEMET) for climatic data. I. Ruano also acknowledges the FPU scholarship program from the Spanish Ministry of Education. Two anonymous reviewers provided valuable comments. A. Blanch revised the English. We also thank J. Olivar for field assistance and C. Herrero and V. Pando for statistical assistance.

Funding Funds for this research were provided through Project AGL2011-29701-C02-02 of the Spanish Ministry of Economy and Competitiveness, the Murcia Regional Forest Service and the Ministry of Science and Innovation through the Technical Support sub-programme and the European Social Fund.

\section{References}

Boydak M (2004) Silvicultural characteristics and natural regeneration of Pinus brutia Ten.- - review. Plant Ecol 171:153-163

Centre de la Propietat Forestal (2004) Annexe Indicadors dendrométrics. In: Generalitat de Catalunya, Departament de Medi Ambient i Habitatge, Centre de la Propietat Forestal (ed) Manual de redacció de plans tècnics de gestió i millota forestal (PTGMF) i plans simples de gestió forestal (PSGF). Instruccions de redacció i l'inventari forestal. Barcelona Spain

Chirino E, Bonet A, Bellot J, Sánchez JR (2006) Effects of 30-year-old Aleppo pine plantations on runoff, soil erosion, and plant diversity in a semi-arid landscape in south eastern Spain. Catena 65:19-29

Daskalakou EN, Thanos CA (1996) Aleppo pine (Pinus halepensis) postfire regeneration: the role of canopy and soil seed banks. Int J Widland Fire 6:59-66

De las Heras J, Moya D, López-Serrano F, Condés S (2007) Reproduction of postfire Pinus halepensis Mill. stands six years after silvicultural treatments. Ann For Sci 64

De las Heras J, Moya D, López-Serrano FR, Rubio E (2012) Carbon sequestration of naturally regenerated Aleppo pine stands in response to early thinning. New Forest. doi:10.1007/s11056012-9356-2

Espelta JM, Verkaik I, Eugenio M, Lloret F (2008) Recurrent wildfires constrain long-term reproduction ability in Pinus halepensis Mill. Int J Wildland Fire 17:579-585

Eugenio M, Verkaik I, Lloret F, Espelta JM (2006) Recruitment and growth decline in Pinus halepensis populations after recurrent wildfires in Catalonia (NE Iberian Peninsula). Forest Ecol Manag 231:47-54

Ganjegunte GK, Condron LM, Clinton PW, Davis MR, Mahieu N (2004) Decomposition and nutrient release from radiata pine (Pinus radiata) coarse woody debris. Forest Ecol Manag 187:197-211

González-Ochoa A, de las Heras J (2002) Effects of post-fire silviculture practices on Pachyrhinus squamosus defoliation levels and growth of Pinus halepensis Mill. Forest Ecol Manag 167:185-194

González-Ochoa AI, López-Serrano FR, de las Heras J (2004) Does post-fire forest Management increase tree growth and cone production in Pinus halepensis? Forest Ecol Manag 188:235-247

Goubitz S, Nathan R, Roitemberg R, Shmida A, Ne'eman G (2004) Canopy seed bank structure in relation to: fire, tree size and density. Plant Ecol 173:191-201

IPCC (2007) Fourth assessment report of the Intergovernamental Panel on Climate Change. Cambridge University Press, United Kingdom and New York, NY, USA

Kollmann F (1959) Tecnología de la madera y sus aplicaciones. Translation of second edition. In: German of 'Tecnologie des Holzes und der Holzwerkstoffe: mit 1194 Abbildungen im Text und 6 Tafeln'. Springer, Berlin, Germany

Kutiel P (1992) Slope aspect effect on soil and vegetation in a Mediterranean ecosystem. Israel J Bot 41:243-250

Madrigal J, Martínez E, Hernando C, Gujarro M, Díez C, Vega JA, Pérez-Gorostiaga $\mathrm{P}$, Fonturbel T, Cuiñas $\mathrm{P}$, Alonso $\mathrm{M}$, Beloso MC (2004) Respuesta a corto plazo del regenerado post-incendio de Pinus pinaster Ait. a clareos mecanizados intensos. Silva lus 12:1-14

Maestre FT, Cortina J (2004) Are Pinus halepensis plantations useful as a restoration tool in semiarid Mediterranean areas? Forest Ecol Manag 198:303-317

Moriondo M, Good P, Durao R, Bindi M, Giannakopoulos C, CorteReal J (2006) Potential impact of climate change on fire risk in the Mediterranean area. Clim Res 31:85-95

Moya D, López-Serrano FR, Condes S, Alberdi I (2009) Structural patterns and biodiversity in burned and managed Aleppo pine stands. Plant Ecol 200:217-228

Navarro FB, Jiménez MN, Gallego E, Ripoll MA (2010a) Short-term effects of overstory reduction and slash mulching on ground vegetation in a Mediterranean Aleppo pine Woodland. Eur J Forest Res 129:689-696

Navarro FB, Jiménez MN, Cañadas EM, Gallego E, Terrón L, Ripoll MA (2010b) Effects of different intensities of overstory thinning on tree growth and understory plant-species productivity in a semi-arid Pinus halepensis Mill. afforestation. Forest Systems 19:410-417

Ne'eman G, Lahav H, Izhaki I (1995) Recovery of vegetation in a natural east Mediterranean pine forest on Mount Carmel, Israel as affected by management strategies. Forest Ecol Manag 75:17-26

Ne'eman G, Goubitz S, Nathan R (2004) Reproductive traits of Pinus halepensis in the light of fire-a critical review. Plant Ecol 171:69-79

Olivar J, Bogino S, Spiecker H, Bravo F (2012) Climate impact on growth dynamic and intra-annual density fluctuations in Aleppo pine (Pinus halepensis) trees of different crown classes. Dendrochronologia 30:35-47

Osem Y, Zangy E, Buey-Moshe E, Moshe Y, Karni N, Nisan Y (2009) The potential of transforming simple structured pine plantations 
into mixed Mediterranean forests through natural regeneration along a rainfall gradient. Forest Ecol Manag 259:14-23

Pausas JG, Ribeiro E, Vallejo R (2004) Post-fire regeneration variability of Pinus halepensis in the Eastern Iberian Peninsula. Forest Ecol Manag 203:251-259

Pérez-Batallón P, Ouro G, Macías F, Merino A (2001) Initial mineralization of organic matter in a forest plantation soil following different logging residue management techniques. Ann For Sci 58:807-818

Regent Instrument Inc., 2002. WindendroTM v. 2002a, Québec, Qc Rivas-Martínez S, Rivas-Sáenz S (1996-2009) Sistema de Clasificación Bioclimática Mundial. Centro de Investigaciones Fitosociológicas, España. http://www.ucm.es/info/cif. Accessed 26 May 2011
Smethurst PJ, Nambiar EKS (1990) Effects of slash and litter management on fluxes of nitrogen and tree growth in a young Pinus radiata plantation. Can J For Res 20:1498-1507

Sternberg M, Shoshany M (2001) Influence of slope aspect on Mediterranean woody formations: comparison of a semiarid and an arid site in Israel. Ecol Res 16:335-345

Tsitsoni T, Ganatsas P, Zagas T, Tsakaldimi M (2004) Dynamics of postfire regeneration of Pinus brutia Ten. in an artificial forest ecosystem of northern Greece. Plant Ecol 171:165-174

Vega JA (2003) Regeneración del género Pinus tras incendios. Cuad Soc Esp Cien For 15:59-68

Verkaik I, Espelta JM (2006) Post-fire regeneration thinning, cone production, serotiny and regeneration age in Pinus halepensis. Forest Ecol Manag 231:155-163 